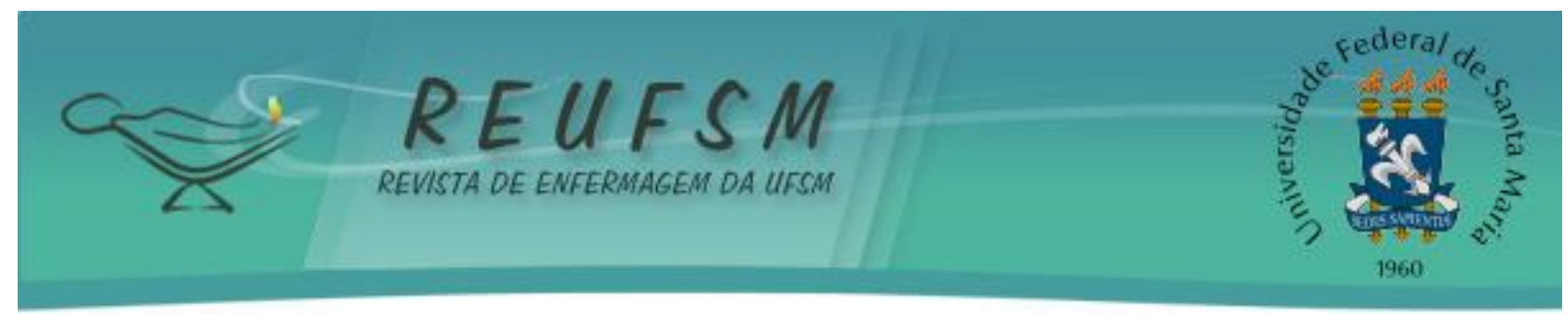

ARTIGO ORIGINAL

\title{
QUALIDADE DE VIDA E CUIDADO DE ENFERMAGEM NA PERCEPÇÃO DE MULHERES MASTECTOMIZADAS*
}

\section{QUALITY OF LIFE AND NURSING CARE IN THE PERCEPTION OF MASTECTOMIZED WOMEN \\ CALIDAD DE VIDA Y CUIDADO DE ENFERMERÍA EN LA PERCEPCIÓN DE MUJERES MASTECTOMIZADAS}

\author{
Natália Gondim de Almeida ${ }^{1}$ \\ Thereza Maria Magalhães Moreira² \\ Ana Karina Bezerra Pinheiro ${ }^{3}$ \\ Juliana Vieira Figueiredo ${ }^{4}$ \\ Ana Virgínia de Melo Fialho ${ }^{5}$
}

Doi: $10.5902 / 2179769217103$

RESUMO: Objetivo: Descrever a percepção de mulheres mastectomizadas acerca dos cuidados de enfermagem recebidos e de sua qualidade de vida. Método: Estudo qualitativo, descritivo, realizado através de entrevistas semiestruturadas com 21 mulheres submetidas à mastectomia, acompanhadas de junho a setembro de 2013 em um ambulatório de mastologia de uma maternidade-escola em Fortaleza, Ceará, Brasil. Os dados foram analisados por meio da análise temática de Minayo. Resultados: Emergiram duas categorias: "Qualidade de vida da mulher mastectomizada" e "Cuidados de enfermagem à mulher mastectomizada". Conclusões: Para a mastectomizada, qualidade de vida está ligada a ter saúde, alimentação saudável, paz, espiritualidade, trabalho e atividade física. Observou-se que o cuidado de enfermagem envolve técnica e teoria, sendo necessário cuidar de forma holística e ética, respeitando aspectos culturais e sociais. A pesquisa espera despertar e sensibilizar novas discussões, com ênfase, principalmente, no cuidado à mastectomizada, com a finalidade de melhorar a qualidade de vida.

Descritores: Enfermagem; Mastectomia; Qualidade de Vida.

ABSTRACT: Aim: To describe the perception of mastectomized women about the nursing care received and their own quality of life. Method: This is a qualitative, descriptive study performed through semi-structured interviews with 21 women who had undergone mastectomy, monitored from June to September 2013 in a mastology outpatient clinic at a maternity-school in Fortaleza, Ceará State, Brazil. Data were subjected to thematic

\footnotetext{
* Oriundo da dissertação intitulada: Qualidade de vida da mulher mastectomizada: espaço para o cuidado clínico de enfermagem, para obtenção do título de mestre pelo Programa de Pós-Graduação Cuidados Clínicos em Enfermagem e Saúde da Universidade Estadual do Ceará.

${ }^{1}$ Enfermeira. Mestre em Cuidados Clínicos em Enfermagem e Saúde pela Universidade Estadual do Ceará UECE. Membro do Grupo de Pesquisa Saúde da Mulher e Enfermagem UECE / Fortaleza/ CE/ Brasil. e-mail: natygondim@gmail.com

${ }^{2}$ Enfermeira. Doutora em Enfermagem pela UFC. Docente do Programa de Pós-graduação Cuidados Clínicos em Enfermagem e Saúde - UECE / Fortaleza/CE/ Brasil. e-mail: tmmmoreira@yahoo.com

${ }^{3}$ Enfermeira. Doutora em Enfermagem pela UFC. Docente do Programa de Pós-graduação em Enfermagem/ Fortaleza/ CE/ Brasil. e-mail: anakarinaufc@hotmail.com

${ }^{4}$ Enfermeira. Mestre em Enfermagem pela Universidade Federal do Piauí - UFPI. Membro do Grupo de Pesquisa Saúde da Mulher e Enfermagem UECE/ Fortaleza/ CE/ Brasil. e-mail: jujuvfigueiredo@yahoo.com.br

${ }^{5}$ Enfermeira. Doutora em Enfermagem pela UFC. Docente do Programa de Pós-graduação Cuidados Clínicos em Enfermagem e Saúde - UECE. Líder do Grupo de Pesquisa Saúde da Mulher e Enfermagem UECE / Fortaleza/ CE/ Brasil. e-mail: anavirginiamf@terra.com.br
} 


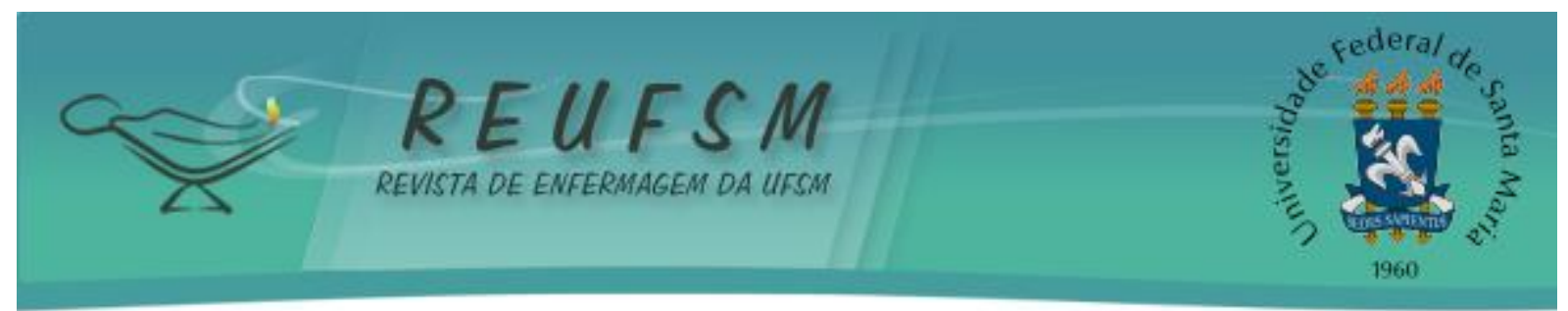

analysis. Results: Two categories emerged: "Mastectomized women's quality of life" and "Nursing care to mastectomized women". Conclusions: For mastectomized women, quality of life is linked to having health, healthy eating, peace, spirituality, work and physical activity. They revealed that nursing care involves technique and theory, requiring care with total comprehension and ethics, respecting cultural and social aspects. The research hopes to encourage and sensitize new discussions, focusing mainly in the care of mastectomized women, in order to improve their quality of life.

Descriptors: Nursing; Mastectomy; Quality of life.

RESUMEN: Objetivo: Describir la percepción de mujeres con mastectomías sobre los cuidados de enfermería y su calidad de vida. Método: estudio cualitativo, descriptivo realizado mediante entrevistas semiestructuradas con 21 mujeres sometidas a la mastectomía, monitoreadas de junio a septiembre de 2013 en un ambulatorio de mastología de una maternidad-escuela en Fortaleza, Estado de Ceará, Brasil. Los datos fueron sometidos a un análisis temático. Resultados: Dos categorías han surgido: "Calidad de vida" y "Cuidados de enfermería" a la mujer con mastectomía. Conclusiones: Para mastectomizadas, calidad de vida está relacionada a tener salud, alimentación sana, paz, espiritualidad, trabajo y actividad física. Revelaron que cuidado de enfermería implica técnica y teoría, atención que requiere holisticidade y ética, respetando aspectos culturales y sociales. La investigación busca despertar y sensibilizar nuevas discusiones, centrándose en el cuidado de la mastectomía, con el fin de mejorar la calidad de vida.

Descriptores: Enfermería; Mastectomía; Calidad de vida.

\section{INTRODUÇÃO}

No Brasil, em 2014, foram estimados 57.120 novos casos de câncer de mama. Desconsiderando os tumores de pele não melanoma, este é o tipo de câncer mais frequente nas mulheres das regiões Sudeste, Sul, Centro-Oeste e Nordeste. ${ }^{1}$

0 câncer de mama causa à mulher possíveis acometimentos e suscetibilidades, em diversos aspectos - biológico, físico, psicológico, espiritual, social e ético, desde o diagnóstico ao tratamento, havendo a necessidade de orientações e cuidados de enfermagem pautados, não apenas no biológico, mas também na melhoria da Qualidade de Vida (QV). ${ }^{2}$

No presente trabalho, em virtude do dissenso acerca de um conceito de QV, adota-se o do World Health Organization Quality of Life (WHOQOL), que o traz como [tradução nossa] "a percepção do indivíduo de sua posição na vida no contexto da cultura e sistema de valores nos quais ele vive e em relação aos seus objetivos, expectativas, padrões e preocupações". 3: 1403-9

A Organização Mundial de Saúde (OMS) ressalta a importância da QV, pois ter saúde significa não apenas viver sem doença, mas viver com qualidade, com direito à saúde, lazer, trabalho e moradia, uma vez que [tradução nossa] "a saúde é um estado de completo bem-estar físico, mental e social, e não consiste apenas na ausência de doença ou de enfermidade". ${ }^{4}$ Requer união de fatores que colaborem para vida saudável, por isso, esse modo de viver tornou-se fonte de pesquisa, a fim de aperfeiçoar o conhecimento e presença de QV na vida das pessoas. ${ }^{5}$

Neste sentido, o câncer de mama pode prejudicar a QV, sobretudo, na presença da ocorrência de mastectomia. ${ }^{6}$ A experiência da mastectomia é potencialmente diferente para cada mulher. Assim, o enfermeiro torna-se importante nesse momento, na tentativa de resgatar o conceito que esta tem de si e do cuidado prestado. ${ }^{7}$ 


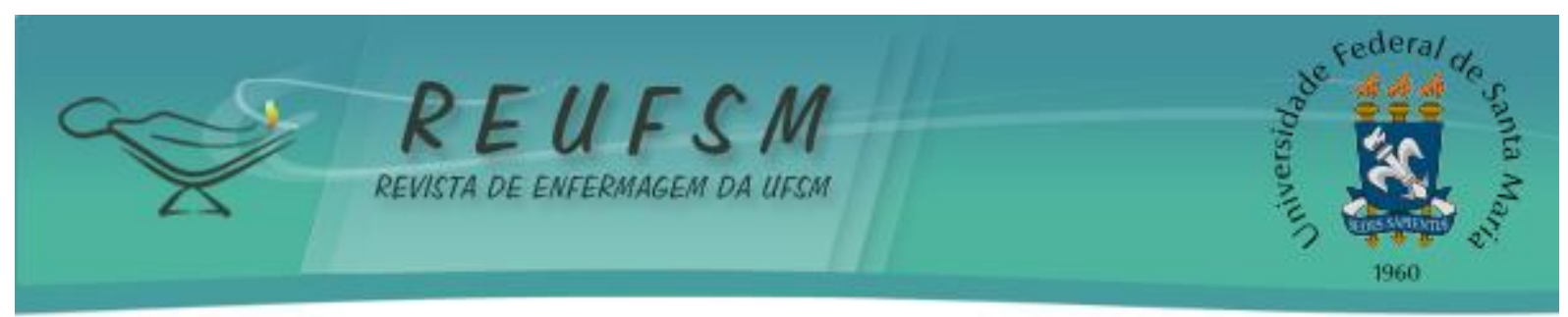

O foco de atuação dos profissionais de enfermagem é o paciente, prestando a este um cuidado, a fim de promover ações que favoreçam seu estado de saúde. Nesta perspectiva, observa-se a relevância do cuidado clínico de enfermagem à mulher com câncer de mama, sobretudo, à mastectomizada. Cuidar requer laços de confiança para que possibilite ações com qualidade e possa influenciar no modo de viver das pessoas. ${ }^{8}$

Diante do exposto e pelo fato de que cada mulher vivenciar o câncer e a mastectomia de maneira singular, questiona-se: como a mulher mastectomizada percebe a sua QV? O que é cuidado de enfermagem para ela? Quais cuidados de enfermagem são por ela recebidos e identificados?

É relevante para a ciência da enfermagem conhecer como a mulher mastectomizada percebe os cuidados e sua Qualidade de Vida após a cirurgia, uma vez que fortalecerá ações de cuidado, colaborando com o processo de trabalho dos profissionais de enfermagem ao englobar as multidimensionalidades - biológica, física, psicológica, espiritual, social e ética em sua prática.

As fragilidades enfrentadas por essas mulheres atraem o olhar de pesquisadores pois, diante do diagnóstico ameaçador, tratamentos prolongados e agressivos, e a incerteza do prognóstico, fazem com que o câncer de mama constitua em um risco para a QV. ${ }^{9}$ Com isso, objetivou-se descrever a percepção de mulheres mastectomizadas acerca dos cuidados de enfermagem recebidos e de sua qualidade de vida.

\section{MÉTODO}

Estudo qualitativo, descritivo, oriundo do projeto "Qualidade de vida da mulher mastectomizada: espaço para o cuidado clínico de enfermagem" aprovado pelo Comitê de Ética em Pesquisa da Maternidade-Escola Assis Chateaubriand (MEAC), com Parecer favorável número 310.165 e 399.467 pelo Comitê de Ética e Pesquisa da Universidade Estadual do Ceará. O cenário foi um ambulatório de mastologia de uma Maternidade Escola de Fortaleza-CE. As participantes do estudo foram mulheres acompanhadas no serviço, submetidas à mastectomia e que compareceram ao retorno pós-cirúrgico de junho a setembro de 2013.

Para definição do tamanho da amostra, foi feito um levantamento do total de cirurgias realizadas no ano de 2012, o que resultou em 96 procedimentos e uma média de oito cirurgias por mês. Com isso, compareceriam para a revisão de cirurgia 24 mulheres. Foram incluídas as mulheres submetidas à mastectomia e atendidas no período de coleta. As que desistiram de participar após ser entrevistada ou que apresentaram respostas confusas não foram incorporadas à análise. De 24 entrevistadas, duas não apresentaram conformidade e ordenação de pensamentos e uma desistiu da participação, totalizando 21 . A fim de manter o anonimato das entrevistadas, foram identificadas pela letra " $M$ " de mulher, seguida de números cardinais.

As entrevistas foram realizadas individualmente, com duração média de 30 minutos, em uma sala no ambulatório reservada, para atender à privacidade da participante, gravadas e, posteriormente, transcritas. Aspectos éticos foram contemplados, visto que o estudo respeitou os preceitos da Resolução 466/2012, do Conselho Nacional de Saúde, que dispõe sobre a necessidade de se tratar o indivíduo com dignidade, respeitando-lhe a autonomia, em defesa de sua autonomia; em compromisso com a beneficência; garantindo a não maleficência; certificando a justiça e equidade. ${ }^{10}$ Foi solicitada a assinatura do Termo de Consentimento Livre e Esclarecido (TCLE) em duas vias, ficando uma com a pesquisadora e outra com a colaboradora. Para a coleta das informações, utilizou-se um roteiro semiestruturado que continha: dados relativos a aspectos sociodemográficos (estado civil, local de moradia, atual ocupação trabalhista, nível de escolaridade, renda 


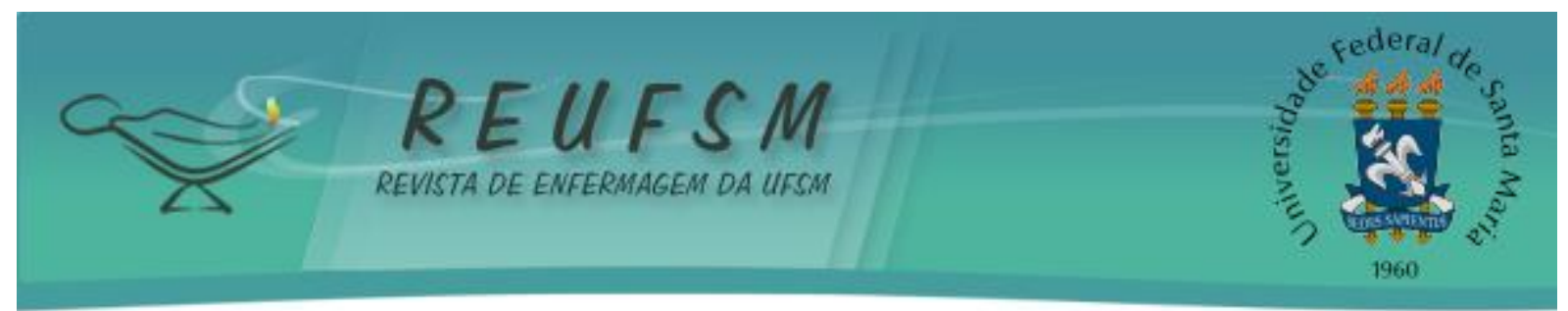

familiar e tempo de que realizou a cirurgia de mastectomia). As perguntas abertas elucidavam questões norteadoras quanto à percepção sobre a QV como: o que você pensa sobre o que é Qualidade de Vida? Quais os profissionais de saúde estiveram presentes e atuaram durante seu acompanhamento no Ambulatório de Mastologia? O que você entende por cuidado de enfermagem? E quais cuidados você recebeu pelos profissionais de enfermagem?

A análise dos dados baseou-se na Análise Temática. O método de escolha é uma das técnicas que melhor se adequa às pesquisas qualitativas. 0 estudo foi desenvolvido em três etapas: pré-análise, a qual consiste na transcrição das falas; exploração do material, que busca classificar e eleger os núcleos de compreensão dos textos; e, por fim, o tratamento dos resultados obtidos e interpretação, que se atenta a analisar as categorias em função dos conteúdos das falas. ${ }^{11}$ Desta, emergiram as categorias: "Qualidade de Vida da mulher mastectomizada" e "Cuidados de enfermagem à mulher mastectomizada".

\section{RESULTADOS E DISCUSSÃO}

As mulheres mastectomizadas participantes tinham idade acima de 39 anos, casadas e provenientes do interior do Ceará. Dedicavam-se as atividades relacionadas ao domicílio, tinham o ensino fundamental incompleto, a renda familiar estava entre dois e três salários mínimos e o tempo de realização da mastectomia foi, em média, de oito a 10 dias.

\section{Qualidade de vida da mulher mastectomizada}

Esta categoria compreende as subcategorias: saúde, alimentação, paz, espiritualidade, viver bem, condições de saúde, trabalho, moradia e atividade física. A QV está ligada à melhor maneira de se viver, à melhoria nas dimensões que envolvem o modo de vida, individualidade e subjetividade, pois depende do ponto de vista individual.

Qualidade de vida [...] a pessoa viver bem, não é? Viver com a saúde da gente [...] viver bem com a minha família [...] viver com muita paz. (M2)

É ter saúde, ter paz em casa, viver com amor, conforto. (M6)

Os dados revelam associação de QV às condições socioeconômicas e culturais. Associa-se à melhoria no padrão de vida, incorporada à sensação de bem-estar, de realização pessoal, qualidade de relacionamentos, educação, estilo de vida, saúde e lazer, enfim, aos aspectos psicológicos, físicos e sociais, além de econômicos. ${ }^{5}$

No entanto, não se tem um conceito propriamente dito, o mais referenciado é o de QV do WHOQOL, por trazer inferência de se viver em diversos aspectos, atribuindo-lhe à multidimensionalidade, o qual mantém forte elo com QV, pois não engloba somente saúde, mas diversos aspectos - biológico, físico, espiritual, social e ético. ${ }^{3-4}$

$\mathrm{Na}$ perspectiva das mulheres submetidas à mastectomia, a QV não é relatada como ausência de doença, mas como um estado de bem-estar, estando relacionada também com o conceito de saúde. Neste cenário, o cuidado de enfermagem subsidia a incorporação de práticas com aspectos multidimensionais que possibilitem uma melhor de QV.

As falas revelam a relação de QV e saúde. Ressalta-se que a retirada de uma mama é um momento de fragilidade para a mulher, o que pode colaborar nessa busca da saúde e o desejo de melhoria clínica. Houve relatos em adquirir hábitos de vida saudáveis, com destaque à alimentação. 


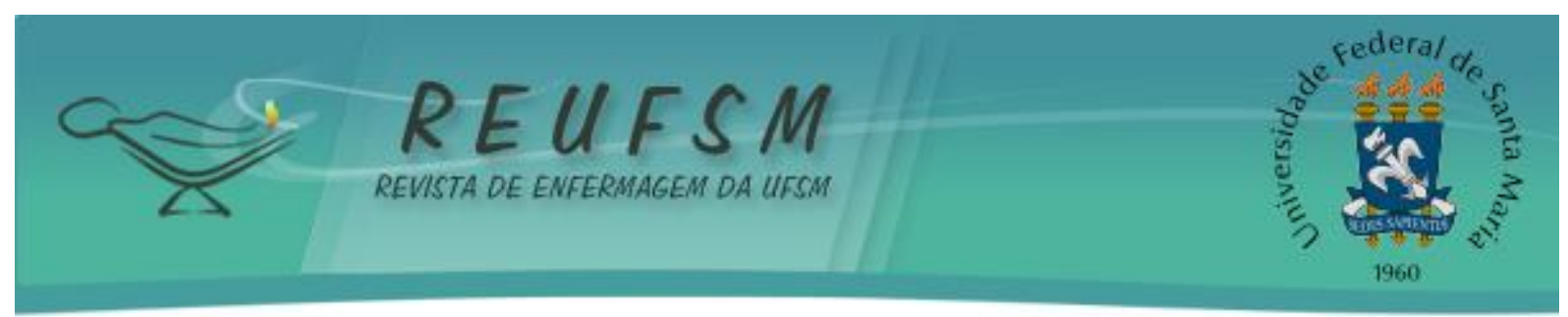

[...] ter um hábito de alimentação bom, ter uma casa boa [...] moradia, saúde. (M4)

[...] alimentar-se bem, não é? [...] paz na família, uma família estruturada, que não haja conflito, os conflitos, essas coisas, é que causam as doenças [...] condição de alimentar-se bem [...]. (M7)

Em virtude de modificações tecnológicas e, consequentemente, do aumento da sobrevida, passou-se a ter maior preocupação em ter boa saúde, dando importância à alimentação saudável. Com isso, a incorporação de alimentos saudáveis vem sendo empregada como estratégia de melhorar a QV, pois podem colaborar minimizando efeitos ruins ocasionados por possíveis problemas de saúde. ${ }^{12}$

0 aumento da expectativa de vida fez crescer o número de pessoas com doenças crônico-degenerativas (diabetes, hipertensão, câncer, entre outras). Em virtude disso, a população tem adotado novos hábitos alimentares, como o consumo de maior quantidade de frutas, verduras, sementes e cereais integrais, os quais suprem as necessidades básicas, e também previnem doenças. ${ }^{13}$

Alimentar-se de forma saudável propicia nutrientes necessários para o desenvolvimento de atividades diárias, favorecendo o sistema imunológico e contribuindo para melhorar o sistema de defesa humoral. ${ }^{13}$ Diante disso e do novo modo de viver das pessoas, buscando uma vida com maior qualidade, há preocupação de incorporar hábitos de vida saudáveis no cotidiano, conforme os achados.

Existe preocupação em incentivar essa prática, pois noções ampliadas em relação à saúde, com ênfase na produção social da saúde, e seus determinantes, como educação, lazer, moradia, saneamento, trabalho, transporte, bem como direito de cidadania, vêm sendo incorporados no cotidiano. ${ }^{14}$ Ressalta-se a ênfase dada à alimentação saudável, provavelmente, em virtude de uma nova percepção, relacionando a ingesta de alimentos às respostas do organismo e aparecimento de doenças, melhorando as condições de saúde e a cicatrização da ferida operatória.

Percebe-se a espiritualidade como fonte de suporte para o enfrentamento da doença por parte dessas mulheres, sendo esta uma forma de fornecer esperança de viver, como as falas que se seguem:

\section{[...] ter paz [...] ter Deus, ter confiança em Deus. (M15) \\ [...] viver com saúde, viver tranquila [...] viver em paz. (M16)}

Nota-se que conceitos de paz e espiritualidade foram usados pelas participantes como sinônimos. A espiritualidade tem sido apontada como importante dimensão da qualidade de vida, pois envolve questões de significado de vida e razão de viver. Salientase que o constructo transcende o campo da saúde, exigindo engajamento de profissionais de diferentes áreas de conhecimento, tornando-a transdisciplinar. ${ }^{15}$

Fé religiosa torna-se meio de fortalecimento para o enfrentamento. É apontada como principal maneira de encarar a doença, sendo o suporte e o sustento fundamental nos momentos de dor e sofrimento durante a neoplasia/tratamento. ${ }^{16}$

Os dados revelam que ter confiança em Deus e ter paz podem modificar como se vê a vida, uma vez que ter fé contribui com a melhora da qualidade de vida, sendo uma dimensão que poderia ser incorporada na prática clínica para que se possa alcançar os objetivos do cuidado, a melhoria de vida da mulher. 


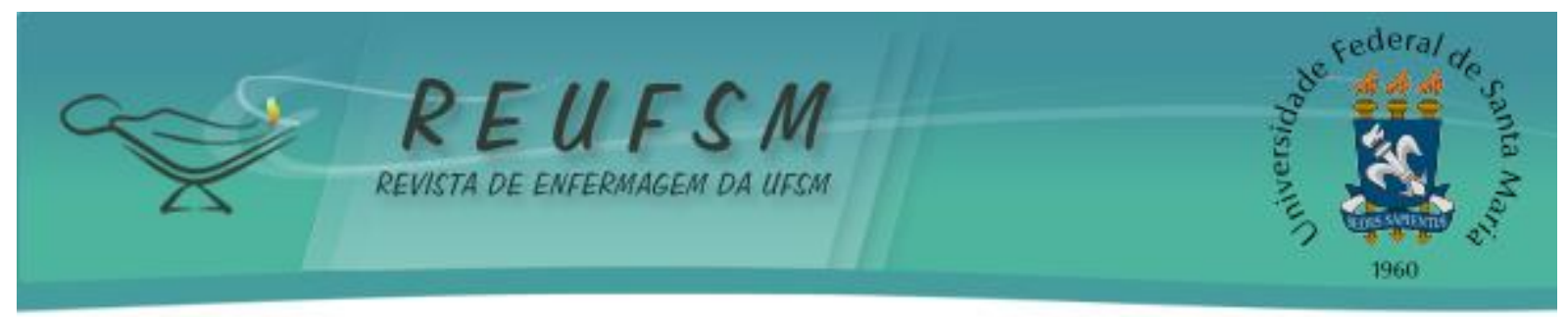

Qualidade de vida é comer bem, é viver bem, em todas as, como se diz? Em todas as partes, viver bem. No caso você chegar aqui e ser bem atendida, é ter sua alimentação, como eu digo? Precisa você ter saúde, né, em primeiro lugar, ter um bom emprego. Conseguir ser atendida, chegar num posto e ser atendida. Porque na verdade as pessoas pagam plano [...] a minha cirurgia, se eu pudesse, já tinha feito há muito tempo, tive que esperar. (M20)

Viver bem em geral e ter uma vida boa são expressões equivalentes com bem-estar, sendo subjetiva diante da QV, felicidade, satisfação com a vida. Parece que viver bem é objetivo fundamental da sociedade moderna. ${ }^{15}$ Assim, em definições acerca de qualidade de vida, há busca pelo estado de bem-estar, o que se atribui à busca do homem por uma vida melhor.

Condições de saúde, forma de acesso, atividades laborais, busca por moradia própria e de qualidade e prática de exercícios físicos estão relacionados à QV e foram citados nos discursos, como revelam as falas a seguir:

Alimentação [...] atividade física, moradia é essa parte. (M1)

[...] praticamente ter uma alimentação, um estudo [...] saúde [...] viver bem, realmente é ter uma moradia [...] um trabalho. (M10)

Qualidade de vida está em alta nas discussões cotidianas, como se percebe nas falas relaciona-se com fatores como: estado de saúde, trabalho, vida social, família, estado emocional, lazer, dinheiro, espiritualidade, entre outros. Dependerá do grau de importância de cada um para que possa chegar a um resultado de se ter ou não QV.

A aquisição de QV interliga-se a diversos aspectos, os quais se relacionam com condições materiais inerentes à sobrevivência e satisfação de necessidades humanas básicas. 0 acesso a um sistema de saúde de qualidade, alimentação adequada e vínculo ocupacional são algumas dessas necessidades. Em virtude de tais aspectos, qualidade de vida não está ligada às condições individuais, mas com várias dimensões, sendo uma construção social a depender da circunstância vivenciada. ${ }^{13}$

\section{Cuidados de enfermagem à mulher mastectomizada}

Nesta categoria, emergiram duas subcategorias: cuidado aliado à técnica e cuidado com afinco.

A ciência da enfermagem vem discutindo o termo cuidado. Trata-se de um conceito desenvolvido nas mais diversas áreas de pesquisa, havendo reflexão em seu entorno. ${ }^{17} \mathrm{~A}$ indagação e análise sobre o que as entrevistadas percebem ser cuidado de enfermagem são apontadas nas seguintes respostas:

[...] o cuidado de enfermagem que é a parte do enfermeiro que vem para aplicar injeção, na hora do remédio [...] pressão, todo aquele acompanhamento que a gente tem quando está internado. (M1)

Cuidado de enfermagem é ter cuidado com uma pessoa que vai fazer um acompanhamento. Fazer um curativo, ter higiene, $o$ máximo de cuidado [...] (M3) 


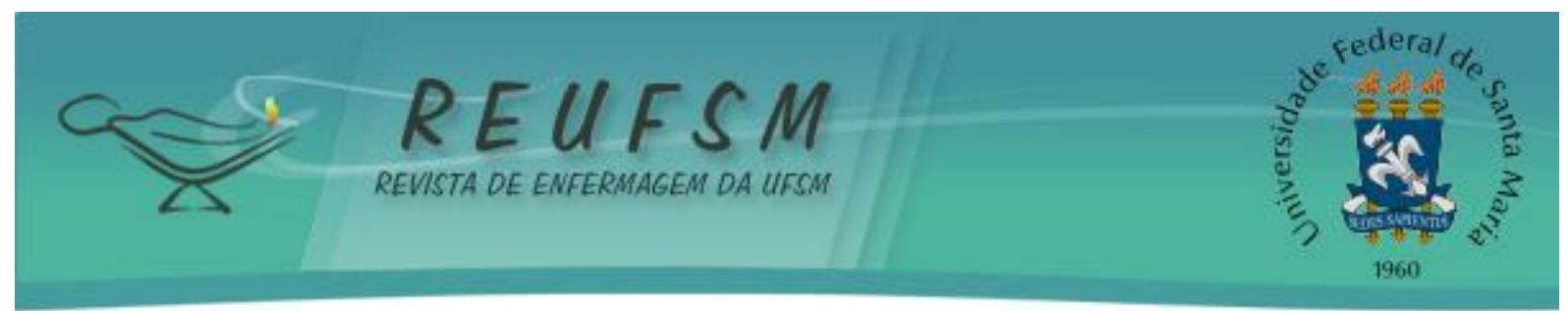

Percebe-se que as mastectomizadas enfatizam cuidados como administração de medicamentos, aferição de pressão arterial e realização de curativos. Não foram mencionados cuidados inerentes às mulheres submetidas à mastectomia, como orientações sobre autocuidado e a mama, a fim de prevenir complicações pós-cirúrgicas.

O cuidado como parte indissociável do tratamento deve ser incorporado nas ações da pratica de enfermagem pois, uma vez retirado o seio, a mulher passa a ter um novo cotidiano, o qual ultrapassa a ótica técnica. Exige, por sua vez, que o profissional de enfermagem tenha valores de cuidado pautados em ações holísticas.

Com relação ao cuidado incorporado à técnica, ressalta-se a presença do cuidado com afinco, com virtudes que vão além da técnica, conforme as falas:

[...] é primeiramente a pessoa ter muito amor pela profissão [...] cuidar do tratamento da gente [...] a enfermeira tem amor à profissão, pois trabalhar com amor é bom. (M7)

É, cuidado de enfermagem é cuidar bem da gente [...] Tratar a gente bem, dar atenção. (M16)

[...] é dedicar-se altamente ao paciente e se tiver algum problema com amor, sem raiva, sem nada. (M17)

O uso de instrumentos, máquinas e os avanços tecnológicos tiveram como consequência uma transformação do fazer, passando a pautá-lo mais em técnicas, acentuando o uso de procedimentos nas ações de cuidado de enfermagem. Espera-se que o foco no tecnicista rompa-se e transcenda para ações pautadas no multidimensional. ${ }^{18}$

Cuidar do outro é complexo e permeia o convívio humano, em sua subjetividade, pluralidade e singularidade. A experiência humana envolve, além da formação de vínculos e trocas mútuas, conflitos, conturbações e animosidades inerentes às relações coletivas. ${ }^{19}$

Com relação aos cuidados percebidos, observou-se a visualização tecnicista, conforme alusões: administração de medicamentos e cuidados de higiene, já educação em saúde/orientação e relacionamento terapêutico foram referidos com menos ênfase.

Apesar de relacionarem cuidado de enfermagem com princípios psicológicos, relação terapêutica e ensino aprendizagem, as participantes dão maior ênfase ao cuidado tecnicista. É importante retomar, no que se refere à mulher que realizou mastectomia, um cuidado que melhore as dimensões afetadas com a retirada do seio, como observado nas seguintes falas:

[...] a enfermeira veio ensinar a gente [...] trocar o dreno [...] elas se comunicavam muito comigo, tinha toda aquela informação. (M1)

[...] medicação, até me banhar me banharam [...] faziam curativos. (M7)

[...] atenção [...] é a conversa, tirar as dúvidas. (M10)

Eu recebi carinho [...] não me deixaram ficar sozinha, sempre tinha uma que estava perto de mim. (M16)

Aquela preocupação de perguntar se a gente estava bem, oferecendo-se, caso precisasse, estavam ali. (M18) 


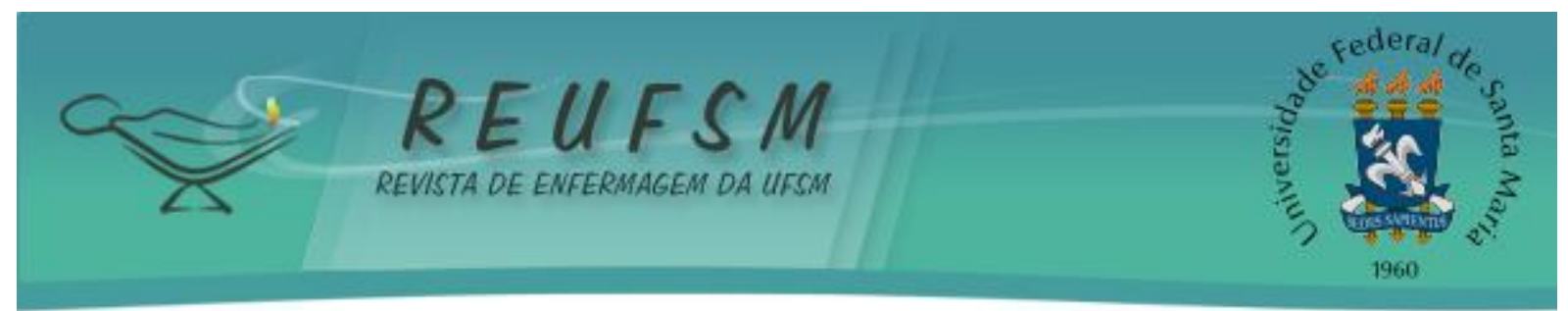

Definir cuidado de enfermagem torna-se difícil, considerando seus diversos conceitos e linhas. As participantes percebem o cuidado de enfermagem como, em sua maior parte, técnica, mas ressalta-se a importância que algumas deram à abordagem humana, com princípios psicológicos, relação terapêutica e ensino aprendizagem.

Romper com o cuidado técnico não é tarefa simples, por isso, faz-se necessário avaliar diversos aspectos na busca da qualidade do cuidado de enfermagem. Entretanto, antes de qualquer mudança, é preciso que haja uma atitude individual, que motive o profissional de enfermagem a ter atos concretos para que rompa com as barreiras pessoais, estruturais e organizacionais que acabam por comprometer a prática. ${ }^{20}$

Há percepção maior sobre cuidados técnicos, administração de medicamentos, verificação de sinais vitais, cuidados com curativos, drenos e higienização. Aludiu-se também o cuidado com afinco como ação à mastectomizada. Como forma de fortalecer o elo com o paciente, a equipe de enfermagem tenta promover práticas de cuidado que faça conexão entre ciência e técnica, objetivando a busca de uma melhora clínica e certificando esse espaço como promotor de saúde e de QV.

Em revisão sistemática, ${ }^{21}$ para identificar práticas de enfermagem que reflitam o modelo de cuidado que assegurasse a manutenção da vida, observa-se quão amplo e complexo é identificá-las. Para entendê-lo, em sua totalidade, torna-se mais difícil quando reduzido apenas à utilização de técnicas que visam somente o biológico e curativo mediante procedimentos. ${ }^{21}$ Nesse contexto, é indispensável atender as necessidades da mastectomizada em sua totalidade.

Cuidar vai além de curar inclui hábitos de vida, crenças e valores. Há cuidados de enfermagem preventivos, de educação sanitária e para manutenção da vida, não menos importantes por não serem curativos. O cuidado transcende procedimentos técnicos através da releitura do papel de suas práticas, a fim de desvencilhar-se de cuidados centrados no modelo biomédico hegemônico, que exalta cuidados curativos e subestima outras formas de cuidar. ${ }^{21}$

O cuidado colabora com a qualidade de sobrevida, ou seja, na forma como a mulher com câncer de mama vive, sendo relevante e importante a busca pela qualificação desse cuidado pelo cuidador. ${ }^{22}$ No que concerne ao cuidado biológico voltado para cura, percebese aproximação com QV. Para as mulheres entrevistadas, está bastante relacionada com a saúde, ou seja, podendo ter relação com a condição de se ter câncer de mama.

Houve referência de médicos, profissionais da enfermagem, psicólogos, nutricionistas e assistentes sociais como profissionais que participaram em alguma fase do tratamento. No entanto, os mais aludidos foram os médicos e os profissionais de enfermagem, estes após indagação de sua participação.

Aqui nesse ambulatório eu tive a presença [...] do médico mastologista [...] enfermeira só quando eu me operei [...] a enfermeira do ambulatório era a senhora loira? (M1)

[...] recebi muito atendimento, de médico, enfermeira [...] psicóloga, teve uma nutricionista. (M8)

Teve muitos que não lembro o nome [...] a nutricionista conversou [...] teve a assistente social [...] psicóloga [...] enfermeira. (M9)

Identificaram-se cuidados, mas, no primeiro momento, as mulheres não sabiam dizer quem era o profissional enfermeiro e algumas não sabiam diferenciar as categorias dos profissionais de enfermagem, configurando todos como enfermeiros. 


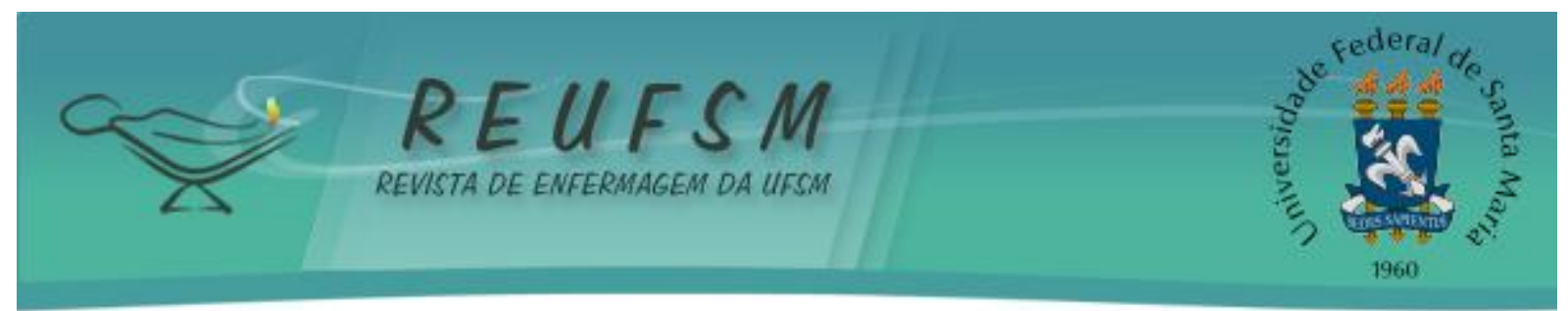

O enfermeiro busca mudar a visão que o receptor do cuidado tem das categorias que compõem a enfermagem. Essa deve ser pautada a partir de uma modificação de atitude do enfermeiro, a qual poderia ser incorporada nas bases e princípios que regem os fundamentos científicos, com a finalidade de anexá-las à prática cotidiana. A construção da imagem de atuação desse profissional adentra aspectos históricos, socioeconômicos e culturais. A população, de uma forma geral, tende a desconhecer a importância e não diferenciar as categorias profissionais que compõem a enfermagem. ${ }^{23}$

0 enfermeiro estabelece intercessões entre conhecimento e linguagem técnica, desenvolve ações que o capacitam para o trabalho em equipe, dando continuidade aos cuidados e articulando experiências empíricas que contemplam uma dimensão estética, ética e pessoal, em que saber fazer não se restringe ao gesto técnico. ${ }^{8}$ Deve-se dar importância ao cuidado prestado pela equipe multiprofissional, pontuando o papel de cada profissional. 0 cuidado à mulher com câncer de mama necessita ser realizado com o desígnio de proporcionar apoio emocional prestado pela enfermagem e equipe multiprofissional, em contribuição à redução de complicações cognitivas, como percepção, atenção, memória, raciocínio e imaginação afetivas e comportamentais decorrentes do tratamento. $^{24}$

\section{CONSIDERAÇÕES FINAIS}

Qualidade de vida é multidimensional e tem o conceito relacionado com as condições de vida individuais. Assim, cada população tem sua definição, e a mulher mastectomizada a percebe como ligada a ter saúde, vinculando-se também à alimentação saudável, além da busca pela paz, espiritualidade, trabalho, moradia e, não menos importante, a prática de atividade física.

Percebe ainda que os cuidados de enfermagem são ações técnicas como administração de medicamentos, troca de soluções, aferição de sinais vitais, troca de curativos, as quais são desenvolvidas na prática do profissional de enfermagem. Aludiram também a importância de um cuidado que fizesse uso de princípios pautados na relação terapêutica, psicologia, orientações e escuta das necessidades individuais.

O cuidado técnico e científico busca um cuidado humano holístico, ético, cultural, social, rompendo com o modelo curativo. Nos cuidados mencionados, houve distanciamento da prática de cuidados específicos para mastectomia. Ressalta-se que os resultados desta investigação têm limitações devido ao fato desta ter sido desenvolvida em apenas um ambulatório. Por isso, não se pode generalizar conclusões a todos os serviços de mastologia.

Por fim, esta pesquisa poderá despertar e sensibilizar novas discussões com ênfase, principalmente, no cuidado específico, buscando aliar a prática e a ciência com a finalidade de melhorar a qualidade de vida, proporcionando cuidado multidimensional a essas mulheres.

\section{REFERÊNCIAS}

1. Ministério da Saúde. Instituto Nacional de Câncer José Alencar Gomes da Silva (Inca). Estimativa 2014: incidência de câncer no Brasil [Internet]. Rio de Janeiro: INCA; 2014 [acesso em 2014 jun 27]. Disponível http://www.inca.gov.br/estimativa/2014/estimativa-24042014.pdf.

2. Olea Gutiérrez CV, Berumen Burciaga LV, Zavala Perez IC. Modelo de cuidado de enfermería para la mujer con cáncer de mama a través de la integración de la dimensión espiritual. ENE Rev de Enfermería. 2012;6(3):1-13. 


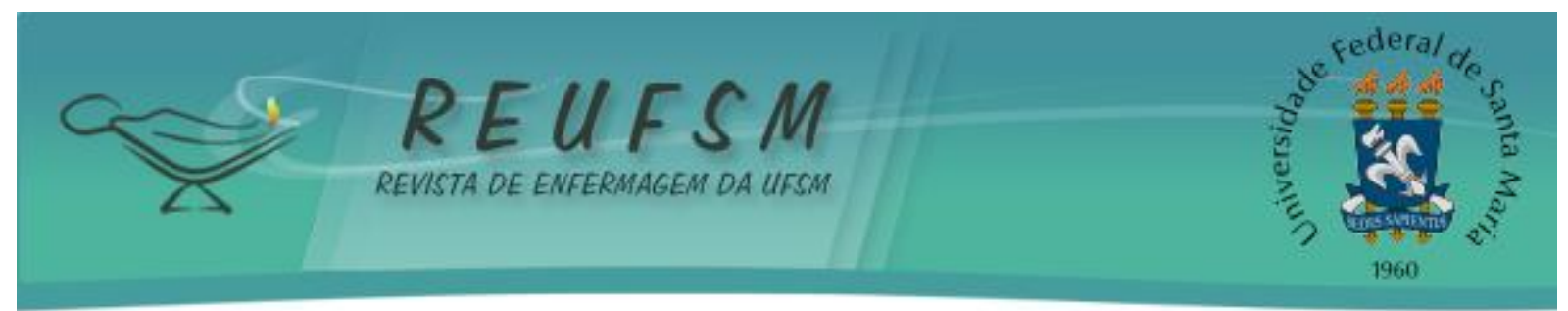

3. The World Health Organization Quality of Life assessment (WHOQOL): position paper from the World Health Organization. Soc Sci Med. 1995;41(10):1403-9.

4. World Health Organization (WHO). Constitution of the World Health Organization. Basic Documents [Internet]. 47a ed. Genebra; 2009 [acesso em 2015 jun 27]. Disponível em: http://apps.who.int/gb/bd/PDF/bd47/EN/basic-documents-47-en.pdf.

5. Fleck MPA, et al. A avaliação de qualidade de vida: guia para profissionais da saúde. Porto Alegre: Artemed; 2008.

6. Instituto Nacional de Câncer José Alencar Gomes da Silva (Inca). Ações de enfermagem para o controle do câncer: uma proposta de integração ensino-serviço [Internet]. $3^{\mathrm{a}}$ ed. rev, atual e ampli. Rio de Janeiro: INCA; 2008 [acesso em 2014 jun 27]. Disponível em: http://bvsms.saude.gov.br/bvs/publicacoes/acoes_enfermagem_controle_cancer.pdf.

7. Instituto Nacional de Câncer José Alencar Gomes da Silva (Inca). Programa Nacional de Controle do Câncer de Mama [Internet]. Rio de Janeiro: INCA, 2010 [acesso em 2014 jun 30]. Disponível em: http://www.oncocir.com.br/wp-content/uploads/2013/01/ProgramaNacional-de-Controle-do-Cancer-de-Mama.pdf.

8. Waldow VR. Bases e princípios do conhecimento e da arte da enfermagem. Petrópolis: Vozes; 2008.

9. Canavarro MC, Pereira M, Moreira H, Paredes T. Qualidade de vida e saúde: aplicações do WHOQOL. Alicerces [Internet]. 2010 [acesso em 2017 jul 7];III(3):243-68. Disponível em: http://repositorio.ipl.pt/bitstream/10400.21/770/1/Qualidade\%20de\%20vida\%20e\%20sa\%C 3\%BAde.pdf.

10. Brasil. Ministério da Saúde. Conselho Nacional de Saúde. Resolução CNS n 466, de 12 de dezembro de 2012. Diretrizes e normas regulamentadoras para pesquisas envolvendo seres humanos (revoga as seguintes resoluções: 196/96, 404/08 e 303/00) [Internet]. Brasília: Ministério da Saúde/CNS; 2012 [acesso em 2015 set 4]. Disponível em: http://conselho.saude.gov.br/resolucoes/2012/Reso466.pdf.

11. Minayo MCS. O desafio do conhecimento: pesquisa qualitativa em saúde. $12^{a}$ ed. São Paulo: Hucitec; 2010.

12. Carvalho JA, Carvalho MP, Alves FA, Barreto MAM. O ensino não-formal como um dos fatores determinantes da qualidade de vida. Práxis (Rio de Janeiro). 2011;3(6):43-8.

13. Vidal AM, Dias DO, Martins ESM, Oliveira RS, Nascimento RMS, Correia MGS. A ingestão de alimentos funcionais e sua contribuição para a diminuição da incidência de doenças. Cad Graduação Cien Biol Saude (Aracaju). 2012;1(1):43-52.

14. Malta DC, Silva MMA, Albuquerque GM, Amorim RCA, Rodrigues GBA, Silva TS, et al. Política Nacional de Promoção da Saúde, descrição da implementação do eixo atividade física e práticas corporais, 2006 a 2014. Rev Bras Ativ Fis Saúde. 2014;19(3):286-99.

15. Ribeiro JL. A importância da qualidade de vida para a psicologia da saúde. In: Cruz JP, Jesus SN, Nunes C, coordenadores. Bem-estar e qualidade de vida. Alcochete: Textiverso; 2009. p. 21-49.

16. Mistura C, Carvalho MFAA, Santos VEP. Mulheres mastectomizadas: vivências frente ao câncer de mama. Rev Enferm UFSM [Internet]. 2011 set/jan [acesso em 2014 jan 2];1(3):351-9. Disponível em: http://cascavel.ufsm.br/revistas/ojs-

2.2.2/index. php/reufsm/article/view/2943/2384. 


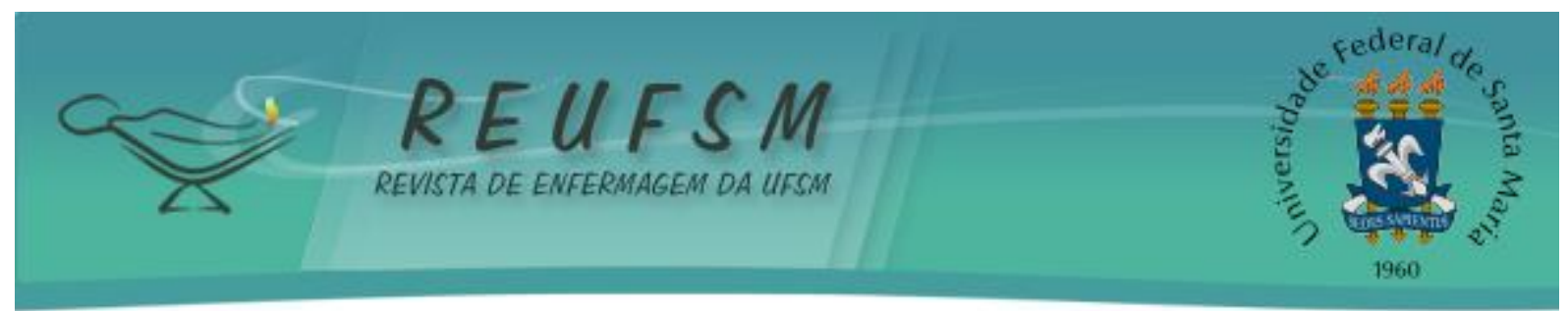

17. Santos JS, Fialho AVM, Rodrigues DP. Influências das famílias no cuidado às mulheres climatéricas. Rev Eletrônica Enferm [Internet]. 2013 jan/mar [acesso em 2014 jan 02];15(1):215-22. Disponível em: www.fen.ufg.br/fen_revista/v15/n1/pdf/v15n1a25.pdf.

18. Thofehrn MB, Amestoy SC, Porto AR, Arrieira ICO, Dal Pai D. A dimensão da subjetividade no processo de trabalho de enfermagem. Rev Enferm Saúde [Internet]. 2011 jan/mar [acesso em 2014 jan 02];1(1):190-8. Disponível em: http://periodicos.ufpel.edu.br/ojs2/index.php/enfermagem/article/viewFile/3423/2814.

19. Baggio MA, Erdmann AL. Relações múltiplas do cuidado de enfermagem: o emergir do cuidado "do nós". Rev Latinoam Enferm [Internet]. 2010 [acesso em 2014 jan 02];18(5):[08 telas]. Disponível em: http://www.scielo.br/pdf/rlae/v18n5/pt_09.pdf.

20. Silva LGC, Haddad MCFL, Vituri DW, Jodas DA, Otrenti E. Dez anos buscando a melhoria da qualidade do cuidado de enfermagem em um hospital universitário. Rev Enferm Atenção Saúde [Internet]. 2012 [acesso em 2014 jun 10];1(1):44-56. Disponível em: http://www.uftm.edu.br/revistaeletronica/index.php/enfer/article/view/328/284.

21. Morais FRC, Silva CMC, Ribeiro MCM, Pinto NRS, Santos I. Resgatando o cuidado de enfermagem como prática de manutenção da vida: concepções de collière. Rev Enferm UERJ [Internet]. $2011 \mathrm{abr} /$ jun [acesso em 2014 jun 10];19(2):305-10. Disponível em: http://www.facenf.uerj.br/v19n2/v19n2a22.pdf.

21. Mendes ABP, Lindolpho MC, Leite AP. La asistencia de la enfermera en la visión de mujeres mastectomizadas. Enferm Glob [Internet]. 2012 [acesso em 2014 jun 10];26:42737. Disponível em: http://dx.doi.org/10.6018/eglobal.11.2.150351.

23. Avila LI, Silveira RS, Lunardi VL, Fernandes GFM, Mancia JR, Silveira JT. Implicações da visibilidade da enfermagem no exercício profissional. Rev Gaúcha Enferm [Internet]. 2013 [acesso em 2014 jun 10];34(3):102-9. Disponível em: http://seer.ufrgs.br/index.php/RevistaGauchadeEnfermagem/article/view/37874/27267.

24. Vieira GB, Sousa RM, Espiríto Santo FH, Teixeira ER. Impacto do câncer na autoimagem do indivíduo: uma revisão integrativa. Rev Baiana Enferm [Internet]. 2012 maio/ago [acesso em 2014 jun 10];26(2):533-40. Disponível em: http://www.portalseer.ufba.br/index.php/enfermagem/article/view/6749/6357.

Data de recebimento: 03/03/2015

Data de aceite: 19/10/2015

Contato do autor responsável: Natália Gondim de Almeida

Endereço postal: Rua Visconde de Mauá, $\mathrm{n}^{\circ}$ 1661, apt ${ }^{\circ}$ 1701, Bl. Rodin, Bairro: Aldeota, Fortaleza, CE.

CEP - 60-125160

E-mail: natygondim@gmail.com 